\title{
Methodology of assessment and reporting of safety in anti-malarial treatment efficacy studies of uncomplicated falciparum malaria in pregnancy: a systematic literature review
}

\author{
Makoto Saito ${ }^{1,2,3^{*}}$, Mary Ellen Gilder ${ }^{3}$, François Nosten ${ }^{2,3}$, Philippe J. Guérin ${ }^{1,2}$ and Rose McGready ${ }^{2,3}$
}

\begin{abstract}
Background: Considering the uncertainty of safety of anti-malarial drugs in pregnancy, efficacy studies are one of the few sources of clinical safety data. Complete safety evaluation is not usually incorporated in efficacy studies due to financial and human resource constraints. This review reports the methods used for the assessment of safety of artemisinin-based and quinine-based treatments in efficacy studies in pregnancy.

Methods: Methodology of assessment and reporting of safety in efficacy studies of artemisinin-based and quininebased treatment in pregnancy was reviewed using seven databases and two clinical trial registries. The protocol was registered to PROSPERO (CRD42017054808).

Results: Of 48 eligible efficacy studies the method of estimation of gestational age was reported in only 32 studies $(67 \%, 32 / 48)$ and ultrasound was used in 18 studies $(38 \%, 18 / 48)$. Seventeen studies $(35 \%, 17 / 48)$ reported parity, 9 $(19 \%, 9 / 48)$ reported gravidity and $13(27 \%, 13 / 48)$ reported both. Thirty-eight studies $(79 \%, 38 / 48)$ followed participants through to pregnancy outcome. Fetal loss was assessed in 34 studies $(89 \%, 34 / 38)$, but the definition of miscarriage and stillbirth were defined only in $11(32 \%, 11 / 34)$ and $7(21 \%, 7 / 34)$ studies, respectively. Preterm birth was assessed in 26 studies $(68 \%, 26 / 38)$ but was defined in 16 studies $(62 \%, 16 / 26)$. Newborn weight was assessed in 30 studies $(79 \%, 30 / 38)$ and length in 10 studies $(26 \%, 10 / 38)$. Assessment of birth weight took gestational age into account in four studies $(13 \%, 4 / 30)$. Congenital abnormalities were reported in 32 studies $(84 \%, 32 / 38)$. Other common risk factors for adverse pregnancy outcomes were not well-reported.

Conclusion: Incomplete reporting and varied methodological assessment of pregnancy outcomes in anti-malarial drug efficacy studies limits comparison across studies. A standard list of minimal necessary parameters to assess and report the safety component of efficacy studies of anti-malarials in pregnancy is proposed.
\end{abstract}

Keywords: Malaria, Pregnancy, Safety, Methodology, Review

\section{Background}

Malaria in pregnancy affects both mother and fetus, regardless of whether the infection is clinically

\footnotetext{
*Correspondence: makoto.saito@wwarn.org

${ }^{2}$ Centre for Tropical Medicine and Global Health, Nuffield Department of Medicine, University of Oxford, Old Road Campus, Roosevelt Drive, Oxford OX3 7FZ, UK

Full list of author information is available at the end of the article
}

symptomatic or not [1-3]. Malaria in pregnancy can lead to higher risks of miscarriage, stillbirth, preterm birth (PTB), low birth weight (LBW), small for gestational age (SGA), and maternal anaemia and mortality [1-3]. PTB, LBW and SGA lead to a higher risk of perinatal mortality $[4,5]$. Maternal mortality attributable to malaria is known to be higher in low transmission settings [2] because of the lower immunity against parasites, and 
may be increased as mid to high endemic areas reduce endemicity to low levels [6]. In the context of declining Plasmodium falciparum malaria prevalence and the emergence of resistant parasite strains of both P. falciparum and Plasmodium vivax, there is a great need for clarity on both efficacy and safety of anti-malarial drugs for the mother and fetus.

Safety reporting of new anti-malarials in pregnancy has not kept pace with release of new drugs in the face of resistance for the non-pregnant populations. The artemisinins are a particular case in point, as rodent and monkey studies consistently reported fetal resorption (embryotoxicity) and congenital abnormalities (teratogenicity). Fetal resorption by artemisinins was considered to be mediated by the depletion of embryonic erythroblasts [7]. For fetal resorption, an added concern was that the level at which adverse effects were seen was very close to the therapeutic range used in humans [7]. The 'no observed' adverse effect level for artemisinin was at $4 \mathrm{mg} / \mathrm{kg} /$ day in monkeys although these adverse events were reported at much longer gestational exposure times than typically given for treatment of malaria (e.g. 12-30 gestational days in monkey studies versus 3-7 days for malaria treatment) [7-12]. Similarly, reticulocytes were reported to be decreased in humans at therapeutic doses, even though human reticulocytes were shown to be less sensitive to artemisinin than embryonic erythroblasts in animals [7]. Major congenital abnormalities were observed in the cynomolgus monkey studies including skeletal (e.g. shortening of the long bones) and cardiovascular malformations [11]. These concerning findings in animal studies emphasize the importance of assessment and reporting of fetal loss, infant cardiac assessment, and infant length following treatment in humans.

Safety of anti-malarials in non-pregnant participants suggested by the World Health Organization (WHO) or the Clinical Data Interchange Standards Consortium (CDISC) includes assessment of symptoms, complete blood count, blood biochemistry, urinalysis, electrocardiogram (ECG) and serious adverse events (deaths, hospitalisations and disability) $[13,14]$. In addition to these general assessments, specific safety outcomes such as miscarriage, stillbirth, congenital abnormality, PTB and SGA are important following anti-malarial treatment in pregnancy. The safety of anti-malarials during human pregnancy has been assessed across continents and in different types of clinical studies [12, 15-21].

The prospective nature of efficacy studies provides a framework for capturing safety data, although the detailed assessment and reporting of safety may not be the main interest. Pathological confirmation of the infection parameters, particularly the parasitological confirmation of malaria parasites, provides an advantage in that characteristics of the disease can be considered in addition to drug treatment. While animal studies raised important concerns, they may have overestimated the risk for humans [21-23] so information from every available source should be utilized to clarify clinical safety of anti-malarial drugs in pregnancy.

This manuscript reviewed the methodology of safety assessment and reporting in the context of artemisininbased (ABT) and quinine-based anti-malarial treatment (QBT) efficacy studies in pregnancy, with a view to developing a guideline for systematic use in future pregnancy studies.

\section{Methods}

A systematic literature review following the methodology described in the PRISMA statement [24] was conducted to identify studies measuring the efficacy of ABT and QBT in pregnant women with parasitologically confirmed uncomplicated falciparum malaria, regardless of trimester or clinical symptoms. Seven different search databases (MEDLINE, Embase, Global Health, Cochrane Library, Scopus, Web of Science and LILACS) and two clinical trial registries (ICTRP and ClinicalTrial.gov) were used. This review was registered to PROSPERO (CRD42017054808) and the search terms and conditions are available in Additional file 1.

Briefly, five elements were used: malaria; pregnancy; treatment (ABT or QBT); study design (interventional or observational cohort); and efficacy. No limitation was set for publication year and language. The search was conducted between July 2016 and January 2017. Two independent assessors checked eligibility and any discrepancy was resolved by a second assessment.

After screening, the following data were extracted: demographic information of study (year, country, study design, study drugs and eligibility criteria), reporting of outcome assessment and definition (pregnancy outcomes and other safety outcomes), reporting of risk factors for the pregnancy outcomes, and the methodology of assessment of variables (method of estimating gestational age and anthropometric measurements). Maternal death, laboratory changes including maternal anaemia, fetal loss, preterm birth, anthropometric measurements, congenital abnormality and neonatal death were reviewed.

Uncomplicated malaria was defined as malaria infection without features of severe malaria [25]. Trimester of the pregnancy was defined as the first $(<13$ completed weeks), the second (14 weeks-27 completed weeks) and the third (from 28 weeks until delivery). Definitions for miscarriage (spontaneous abortion), stillbirth, preterm delivery, low birth weight, neonatal death were summarised across the studies. 


\section{Results}

A total of 48 studies assessing treatment efficacy of ABT or QBT for uncomplicated falciparum malaria in pregnancy were retrieved (see Additional file 2). A total of 7111 women with confirmed falciparum malaria were enrolled in those trials, 6147 and 964 participants were treated with ABT or QBT, respectively. Forty-one were published, five presented at conferences and two registered but not yet published.

There were 22 randomized control trials (RCTs) comparing two or more treatment regimens [26-48], ten pharmacokinetic (PK) studies including clinical outcome assessment [49-59], six single arm interventional studies [60-65] and ten observational cohort studies [66-76] (see Additional file 3).

\section{Obstetric care and characteristics of participants Gestational age}

Thirty-two studies $(67 \%, 32 / 48)$ reported estimated gestational at the time of the malaria episode in weeks $(\mathrm{n}=31)$ or in months $(\mathrm{n}=1)$ [37]. Nine studies $(19 \%$, 9/48) did not report gestational age but reported the trimester of the malaria episode [26, 27, 38, 40, 41, 54, 59, $66,75]$. One RCT [29] did not report gestational age or trimester, and information was not available from six unpublished studies $[44,47,48,55,64,72]$.

Thirty-two studies $(67 \%, 32 / 48)$ reported the method for estimating gestational age (see Additional file 3). Among them, ultrasound was used for at least some women in 18 studies (38\%, 18/48). Newborn examination for gestational age estimation was used in another 12 studies $(25 \%, 12 / 48)$ using the Dubowitz $(19 \%, 9 / 48)$ or Ballard score $(6 \%, 3 / 48)$. Last menstrual period and symphysis fundal height were the only methods of estimating gestational age in two studies $(4 \%, 2 / 48)$. Quality control of gestational age estimation was mentioned in two studies $[41,53]$.

\section{Parity and gravidity}

Seventeen studies $(35 \%, 17 / 48)$ reported parity, 9 (19\%, 9/48) reported gravidity and $13(27 \%, 13 / 48)$ reported both (see Additional file 3). Only three published studies $(6 \%, 3 / 48)$ did not report either. Information was not available from six unpublished studies.

\section{Antenatal follow-up after malaria efficacy assessment}

Thirty-eight studies $(79 \%, 38 / 48)$ followed participants until pregnancy outcome (see Additional file 3). Ten studies did not specify the follow-up of participants after the primary endpoint of efficacy (e.g. day 28-63).

\section{Assessment of maternal safety \\ Maternal deaths}

Maternal deaths were reported in 13 out of 46 published or presented studies, including four studies with no maternal deaths $(28 \%, 13 / 46)$. [26, 31, 33, 36, 37, 39-41, $43,61,63,68,74]$.

\section{Maternal anaemia and other laboratory investigations}

Thirty-nine $(81 \%, 39 / 48)$ studies reported haematological assessment at least once during the study. Of them, 20 studies $(51 \%, 20 / 39)$ used haematocrit [28-33, 36, 48, $49,51-53,66-71,73], 17$ studies $(44 \%, 17 / 39)$ used haemoglobin [34, 35, 37, 39-41, 43, 50, 54, 56, 57, 60-64, 75] and two studies $(5 \%, 2 / 39)$ used both $[46,65]$. Four published studies did not report haematological assessment $[26,38,59,74]$ and information was not available in five unpublished studies $[27,44,47,55,72]$. Twenty-five studies $(52 \%, 25 / 48)$ continued assessing maternal anaemia after the primary endpoint of efficacy (e.g. day 28-63) regularly or only at delivery $[30-33,35,36,39,41,43,48$, 49, 52-54, 60, 61, 63, 64, 66-68, 70, 71, 73, 75]. Seventeen (35\%, 17/48) studies specified the use of haematinics: 15 provided iron and folic acid [31, 33, 35-37, 39, 41, 48, 52, $53,67,68,70,73,75]$; and two did not explain the details [38, 54].

Reporting of other laboratory investigations was summarized in Additional file 4.

\section{Assessment of fetal safety \\ Fetal loss}

Fetal loss was assessed in 34 studies $(89 \%, 34 / 38)$ out of the 38 which followed through to pregnancy outcome (see Additional file 5) and not reported in three published studies [54, 62, 69] and one registered trial [47]. An additional two studies $(20 \%, 2 / 10)$ out of ten studies without specified follow-up past the efficacy endpoint still reported pregnancy loss during the study period $[28,56]$.

Miscarriage was defined in 11 studies (32\%, 11/34). Miscarriage was defined as fetal loss before 28 weeks' gestation in ten studies [33, 35, 43, 50, 60, 61, 66-68, 70]. One study defined miscarriage as fetal loss $<20$ weeks and intrauterine fetal death as fetal loss $>20$ weeks [39]. Six studies did not define the term but reported miscarriage $[26,31,36,41,45,74]$.

Stillbirth was defined in seven studies $(21 \%, 7 / 34)$ [33, $35,39,43,66,68,70]$. Six studies used the cut-off of 28 weeks gestation or more, and one study used 21 weeks [39]. Nine studies did not give a definition but reported stillbirth [32, 36, 37, 41, 44, 45, 66, 74, 75]. 


\section{Preterm birth}

Eleven studies reported the mean or median estimated gestational age at delivery $[30-33,35,36,39,49,52,64$, 66-68, 70, 71, 75] (see Additional file 5). Five studies only included singletons for the summary calculation [31, 33, $36,68,70]$. Twenty-six studies $(68 \%, 26 / 38)$ assessed PTB or prematurity of the newborn. Ten studies $(26 \%, 10 / 38)$ did not report whether they assessed PTB or not [30, 37, $45,51,53,54,62,66,67,69]$, and information was not available from two unpublished studies [44, 47].

PTB was defined in 16 studies $(62 \%, 16 / 26)$. All of them used the cut-off of $<37$ weeks' gestation. Two used $>28$ weeks as the lower boundary $[50,60]$ and one study differentiated those born $<28$ weeks as severe prematurity [39]. Six of them defined PTB but did not report the results $[31,32,35,60,68,70]$. Seven studies did not define but did reported PTB [26, 27, 52, 61, 64, 71, 74]. In two studies, all deliveries were full-term [29, 63]. One unpublished study plans to assess PTB [48].

\section{Anthropometric assessment of newborns}

Birth weight was assessed in 30 studies (79\%, 30/38) (see Additional file 6). LBW was reported in 19 studies (63\%, $19 / 30)$. LBW was defined in 18 studies $(60 \%, 18 / 30)$ but one of them did not report the result [66]. Birthweight of less than $2500 \mathrm{~g}$ was used as the cut-off regardless of the estimated gestational age at delivery with an exception of one study which included $2500 \mathrm{~g}$ as LBW [51]. Two studies did not define LBW but reported the proportion [31, 32]. Four studies reported birth weight related to gestational age at delivery (i.e. small for gestational age comparing to the WHO growth curve [75] or body weight of term babies only $[36,39,74])$. Only singleton births were included in the calculation of the average birthweight in eight studies [31-33, 36, 41, 68, 70, 73], and women with multiple gestations were excluded from the study in four studies [35, 37, 43, 44]. All women delivered singletons in four additional studies $[49,51,52,71]$. Gender of the newborns, which affects birth weight, was only reported to be assessed in six studies $(16 \%, 6 / 38)[33,48-50,52$, 75 ] and was used for body weight assessment in one of them [75].

Length of newborns was assessed in ten studies $(26 \%$, $10 / 38)$ and four of them $(11 \%, 4 / 38)$ reported the results $[33,36,64,74]$. Head circumference of newborns was assessed in 11 studies $(29 \%, 11 / 38)$ and five of them $(14 \%$, $5 / 37)$ reported the results $[33,36,61,63,74]$. Length and head circumference were reported in term babies only in one study [74], and estimated gestational age was not considered in other studies.

The timing of anthropometric assessment was specified in 12 studies $(32 \%, 12 / 38)$ : within $24 \mathrm{~h}(\mathrm{n}=5)$ [30, 33, 35, $61,63], 48 \mathrm{~h}(\mathrm{n}=1)[64], 72 \mathrm{~h}(\mathrm{n}=4)[36,41,52,73]$ and
5 days $(n=1)$ [49]. One registered trial specified the timing as 'as soon as possible after delivery' [48]. Five studies $(17 \%, 5 / 30)$ specified the minimal precision of the body weight scales used [31, 32, 52-54] and one study specified the minimum digit of the measurement [35]. Only 2 of 19 RCTs which followed women until delivery $(10 \%$, $2 / 19)$ stated that the physical assessment of babies was done by blinded investigators [36, 39].

\section{Congenital abnormality}

Thirty-two studies $(84 \%, 32 / 38)$ reported the presence of any congenital abnormalities. Six studies $(16 \%, 6 / 38)$ did not report whether there were any newborns with congenital abnormality [26, 34, 45, 62, 69, 75]. No studies reported that cardiac auscultation was specifically performed except one study in which newborn heart sounds were systematically documented [36]. Only one infant with congenital heart diseases was reported, and the estimated gestational age at drug exposure was 19 weeks [39]. Twenty-five studies (66\%, 25/38) followed the newborns for a period (from 6 weeks to 3 years) after delivery to assess mortality, congenital abnormality and development (see Additional file 6). At least six different methods of developmental assessment [77-82] were used in eight studies [29, 30, 33, 36, 39, 48, 52, 74] and three other studies reported using developmental milestones $[31,32,50]$.

\section{Neonatal mortality and condition of newborns at birth}

APGAR score was assessed in four studies $(11 \%, 4 / 38)$ $[30,39,41,74]$, and only one of them reported the results [30]. Neonatal jaundice was assessed in seven studies $(18 \%, 7 / 38)[29,30,35,37,41,43,74]$, and four of them reported the results $[29,30,35,37]$. Neonatal death was defined in six studies $(16 \%, 6 / 38)$ (see Additional file 5). Two of them reported early neonatal death defined by death within the first week of life [39, 74]. Four studies used a month: a month [53, 73], 27 days [35] and 32 days [36]. Perinatal death was defined in two studies $(5 \%, 2 / 38)$. One study included miscarriage, stillbirth and neonatal death (within 27 days after birth) [35]. The other study defined it as death from 28 weeks gestational age until 1 week after delivery [60]. Sixteen studies (42\%, $16 / 38$ ) did not define but reported the deaths of newborns after delivery $[26,31-34,37,43,44,52,60,61,63$, $64,66,71,75]$.

\section{Associated obstetric risk factors for adverse pregnancy outcomes}

Risk factors for adverse pregnancy outcomes were not well-reported (see Additional file 7). The previous history of pregnancy loss was considered in two studies (4\%, $2 / 48$ ), which excluded women with a history of multiple 
miscarriage or stillbirths [37, 41]. All other studies (96\%, 46/48) did not report the previous history of pregnancy loss. Except one study reporting the history of previous preterm birth to explain a neonatal death [33], the histories of previous preterm birth or low birth weight were not reported in any other studies. In 21 studies (44\%, $21 / 48$ ), women with known chronic diseases (including $\mathrm{renal} /$ hepatic/cardiac/mental diseases) were excluded from the study. One study reported the proportion of women with diabetes [74] and another study reported there were no women with chronic diseases included [56]. No studies reported the history of non-malarial febrile illness during the pregnancy but two studies excluded women with other diseases associated with fever [46] or severe underlying diseases presenting with fever [65]. Ten studies mentioned HIV status of the participants. Four studies included women with $\operatorname{HIV}[35,37$, $39,45]$. Two studies included women with HIV only if cotrimoxazole prophylaxis (and antiretroviral treatment) was not administered [41, 75]. Four studies excluded women with HIV [43, 44, 51, 57].

Smoking status was assessed in six studies $(13 \%, 6 / 48)$ $[36,39,48,52,53,56]$. One published study assessed the smoking status, but did not report it [39]. Women with a history of alcohol (or narcotic abuse) were excluded in four studies $(8 \%, 4 / 48)[33,36,48,49]$, and alcohol consumption was not reported in any other studies. One study reported the use of traditional medicine in the description of a stillbirth [35], and two studies excluded women who used herbal medicine in the past 4 weeks at enrolment $[46,65]$. Marital status was reported in three studies $(6 \%, 3 / 48)[35,54,75]$. Consanguinity was reported as a possible reason for a stillbirth in a study [36]. Education level was reported in eight studies (17\%, $8 / 48$ ) $[35,37,38,43,48,51,54,75]$. Maternal height was assessed in eleven studies $(23 \%, 11 / 48)[30,43,46,48$, $50,51,53,54,56,65,67]$, and five of them also reported body mass index (BMI) $[46,51,54,56,65]$. Three studies reported BMI without the maternal height [36, 52, 57]. No studies reported any other nutritional status assessment. The number of antenatal care visits was not reported except one study reporting the proportion of women who attended the antenatal clinic at least two times [54].

\section{Discussion}

This literature search revealed the variability of antimalarial safety reporting in treatment efficacy studies in pregnancy. Understandably, pregnancy outcomes remain secondary to the primary objective of anti-malarial efficacy studies and reporting of safety outcomes may have been omitted or truncated to meet journal length restrictions. Safety assessment in the context of malaria is further stymied by the paucity of reliable background data on pregnancy outcomes and early childhood norms in the target populations in low and middle-income countries [15]. Methodological difficulties, variability of definitions and measurement of key indicators, such as gestational age and birth weight [83], and lack of integrated malaria, antenatal and delivery activities prevents confident pooling of published data which could potentially fill the gaps of current knowledge about the safety of anti-malarials in pregnancy.

Pregnancy outcomes can be affected by many factors. Malaria can affect pregnancy outcomes by acute disease effects (e.g. fever), acute and chronic effects (e.g. placental sequestration), and drug effects. Fever by non-malaria causes, common in tropical areas, can cause pregnancy loss or preterm labour [84]. Placental sequestration can cause inflammation of the placenta and reduction in the blood flow to the placenta, which lead to impaired placental function and intrauterine growth restriction [85-87].

For meaningful interpretation of pregnancy outcomes, gestational age needs specific attention [88] as it is necessary for interpretation of laboratory results, infant birth weight (as appropriate, large, or small for gestational age), as well as to evaluate the likelihood that a certain drug exposure could have a causative relationship with an adverse outcome. Preterm delivery and miscarriage are important outcomes associated both with infection and certain medications, and can only be evaluated with accurate estimation of gestational age. However, gestational age was assessed differently across the included studies and with each method there is invariably a degree of increasing error as pregnancy progresses: after 24 weeks ultrasound cannot reliably determine gestational age and last menstrual period becomes more difficult to recall. Gestational age assessment relies on quality control, which was often not reported. Modifying superficial and neurological items in clinical newborn gestational age assessment reduces the accuracy of these tests [89].

Laboratory results differ from non-pregnant participants due to the physiological changes of gestation [90]. Although haematologic markers were commonly assessed, the physiological change of haemoglobin over pregnancy [91] was not considered. A simple comparison between one measurement at the time of malaria and one at delivery may not estimate the effect of malaria or antimalarials correctly. The impact of repeated malaria infection needs to be assessed.

As exposures to artemisinin derivatives in early pregnancy were shown to be related to cardiovascular abnormalities in animal studies [12], echocardiography should be ideally used but is rarely feasible in low resource 
settings. In the absence of echocardiography, serial cardiac auscultation and clinical exams could be used to identify murmurs, signs of congestive heart failure, or cyanosis. Unfortunately, affected children are often difficult to identify against the high background incidence of respiratory infections [92, 93]. Shortening of long bones is also reported in animal studies, and length of the newborn should be measured and compared to a standard that accounts for sex and an adequately estimated gestational age. Ongoing follow up and clinical exams to assess the development of infants can be useful to detect musculoskeletal abnormalities. Mode of feeding and other morbidities including malaria, need to be considered in the developmental assessment. In addition to the technical difficulties of developmental assessment, efficacy studies are unlikely to provide sufficient numbers of participants to assess for congenital abnormalities (which are rare) [94], and it will be necessary to combine data from these studies with information from other sources.

It is difficult to compare birthweight between studies and even between different study arms in anti-malarial efficacy trials. Assessment and comparison require a precise scale as the reported magnitude of reduction in birthweight is 35-310 g [1]. However, comparison with this precision is difficult because of the variability of methodology, inaccuracy of measurements and lack of information on confounding factors [83]. Firstly, birthweight for comparison should be measured in undressed live singleton newborns without any apparent congenital abnormalities within $24 \mathrm{~h}$. Body weight on day $3-5$ can physiologically be $\geq 10 \%$ lower than the birthweight $[95,96]$. Accuracy and precision of the body weight scale

Table 1 Recommendations for reporting anti-malarial drug safety in pregnancy in efficacy studies

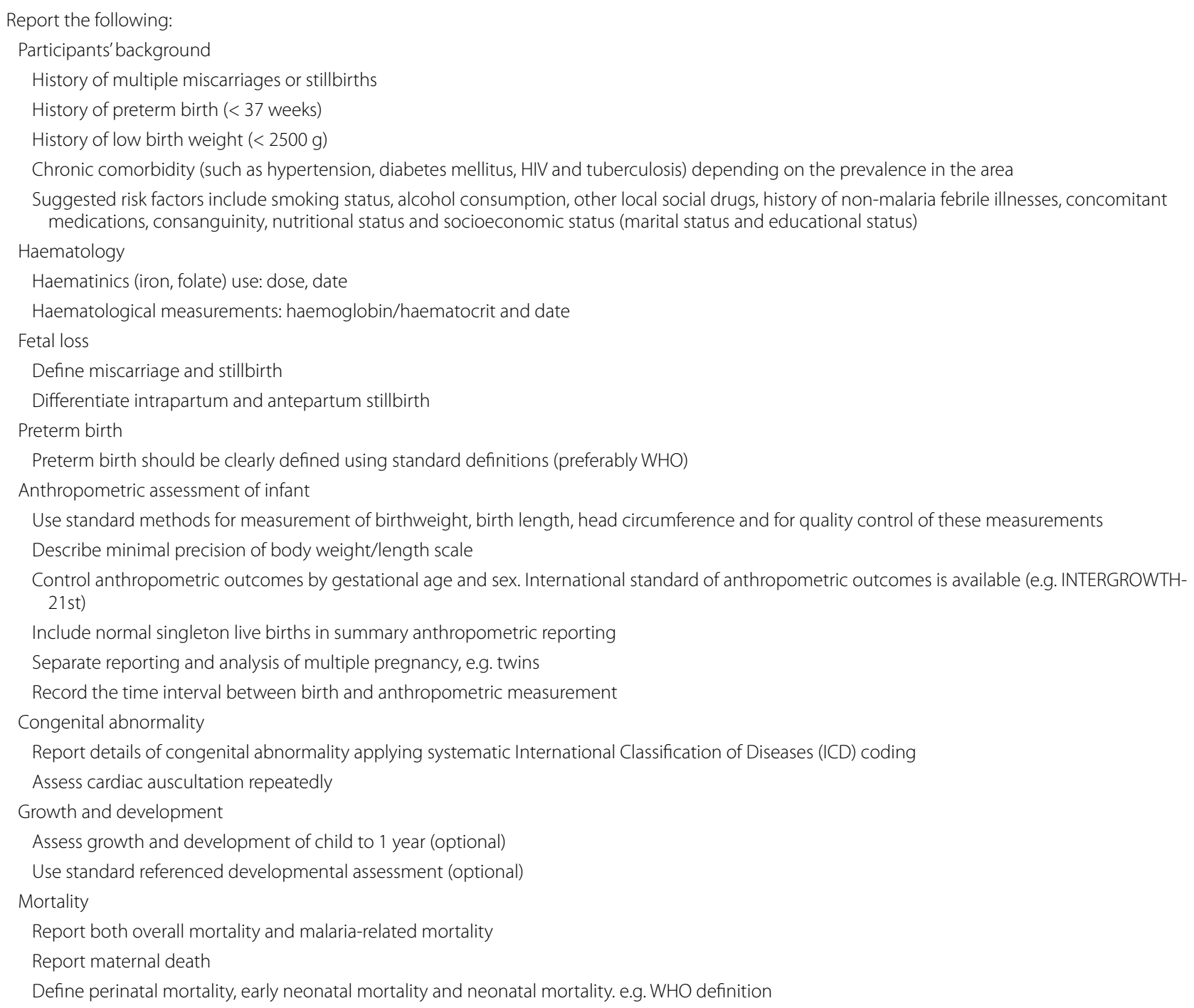


also need to be specified before concluding the difference in different treatment arms. Secondly, birthweight is affected by the gestational age and sex. Preterm babies are more likely to be categorized as being LBW, but LBW does not necessarily equate to SGA [97]. LBW infants include a mixture of preterm and intra-uterine growth restricted babies, and these categories should be distinguished as they reflect different aetiologies and outcomes. The impact of malaria on birthweight is more accurately assessed using SGA [97]. International standards to assess birthweight adjusted for gestational age and sex are available such as INTERGROWTH-21st, which also covers populations in malaria endemic areas [88].

It is necessary to determine whether adverse outcomes are related to treatment rather than malaria. This can be only done when the risk is compared between different treatments or to a well-established population prevalence. Several risk factors for adverse pregnancy outcomes, such as smoking, hypertension, low BMI and primigravida were also reported in malaria endemic settings [97] and there are some other potential local risk factors such as traditional medicine and consanguinity. These should be recorded and assessed, especially in non-comparative studies [23]. Parity and gravidity were not consistently reported and if some manuscripts report parity and others gravidity, pooling of data becomes difficult. A distinction between antepartum stillbirth and intrapartum stillbirth is important, as intrapartum stillbirth is mainly affected by the availability and the level of delivery support [98]. Finally, the impact of the timing and frequency of malaria episodes and drug administration in each pregnancy need to be assessed with parasitological confirmation [99], and this is most appropriately done in prospective studies. A simple checklist of for reporting pregnancy-related information in anti-malarial efficacy studies is provided (Table 1).

\section{Conclusions}

Much is still not known about the impact of anti-malarial treatment on the consequences of malaria infection in pregnancy. Every effort should be made to make the most of each treatment episode in an efficacy study by gathering a minimal set of important safety data to fill this knowledge gap. This valuable data can then be pooled with data from other sources of clinical safety information such as pharmacovigilance studies or exposure registry to strengthen safety conclusions. Standardization of assessment and reporting will be a foundation for research with more comparable and reliable outputs and will generate the needed evidence to guide policy.

\section{Additional files}

Additional file 1. Search terms for literature review.

Additional file 2. PRISMA flowchart.

Additional file 3. Summary of the study design and reported outcomes. Additional file 4. Summary of the assessment of non-obstetric acute safety.

Additional file 5. Definition and reporting of fetal losses and prematurity of newborns.

Additional file 6. Anthropometric and developmental assessment of the newborns.

Additional file 7. Assessment and reporting of risk factors of adverse pregnancy outcomes.

\section{Abbreviations}

ABT: artemisinin-based treatments; BMI: body mass index; CDISC: Clinical Data Interchange Standards Consortium; ECG: electrocardiogram; ICD: International Classification of Diseases; LBW: low birth weight; PK: pharmacokinetic; PTB: preterm birth; QBT: quinine-based treatments; RCT: randomized control trial; SGA: small for gestational age; WHO: World Health Organization.

\section{Authors' contributions}

MS and MEG did literature search. MS analysed the extracted information and wrote the first draft of the manuscript. MEG, FN, PJG and RM contributed significantly to the writing of the manuscript. All authors read and approved the final manuscript.

\section{Author details}

${ }^{1}$ WorldWide Antimalarial Resistance Network (WWARN), Oxford, UK. ${ }^{2}$ Centre for Tropical Medicine and Global Health, Nuffield Department of Medicine, University of Oxford, Old Road Campus, Roosevelt Drive, Oxford OX3 7FZ, UK. ${ }^{3}$ Shoklo Malaria Research Unit (SMRU), Mahidol-Oxford Tropical Medicine Research Unit, Faculty of Tropical Medicine, Mahidol University, Mae Sot, Tak, Thailand.

\section{Acknowledgements \\ The authors thank all the healthcare workers and pregnant women who contributed to this body of research.}

\section{Competing interests}

The authors declare that they have no competing interests.

Availability of data and materials

The extracted data will be available at WWARN website (http://www.wwarn. org/).

Consent for publication

Not applicable.

Ethics approval and consent to participate

Not applicable.

Funding

WWARN is supported by the Bill \& Melinda Gates Foundation. SMRU is part of the Mahidol Oxford University Research Unit supported by the Wellcome Trust of Great Britain. MS is currently supported by the University of Oxford Clarendon Fund. The funding bodies do not have roles in this review.

\section{Publisher's Note}

Springer Nature remains neutral with regard to jurisdictional claims in published maps and institutional affiliations. 
Received: 23 October 2017 Accepted: 5 December 2017 Published online: 18 December 2017

\section{References}

1. Desai M, ter Kuile FO, Nosten F, McGready R, Asamoa K, Brabin B, et al. Epidemiology and burden of malaria in pregnancy. Lancet Infect Dis. 2007;7:93-104.

2. Rijken MJ, McGready R, Boel ME, Poespoprodjo R, Singh N, Syafruddin D et al. Malaria in pregnancy in the Asia-Pacific region. Lancet Infect Dis. 2012;12:75-88.

3. Moore KA, Simpson JA, Wiladphaingern J, Min AM, Pimanpanarak M, Paw MK, et al. Influence of the number and timing of malaria episodes during pregnancy on prematurity and small-for-gestational-age in an area of low transmission. BMC Med. 2017;15:117.

4. Moore KA, Fowkes FJI, Wiladphaingern J, Wai NS, Paw MK, Pimanpanarak $\mathrm{M}$, et al. Mediation of the effect of malaria in pregnancy on stillbirth and neonatal death in an area of low transmission: observational data analysis. BMC Med. 2017:15:98

5. Katz J, Lee AC, Kozuki N, Lawn JE, Cousens S, Blencowe H, et al. Mortality risk in preterm and small-for-gestational-age infants in low-income and middle-income countries: a pooled country analysis. Lancet. 2013:382:417-25

6. Mayor A, Bardaji A, Macete E, Nhampossa T, Fonseca AM, Gonzalez R. Changing trends in P. falciparum burden, immunity, and disease in pregnancy. N Engl J Med. 2015;373:1607-17.

7. Clark RL. Embryotoxicity of the artemisinin antimalarials and potential consequences for use in women in the first trimester. Reprod Toxicol. 2009;28:285-96.

8. Li Q, Weina PJ. Severe embryotoxicity of artemisinin derivatives in experimental animals, but possibly safe in pregnant women. Molecules. 2010;15:40-57.

9. White TE, Clark RL. Sensitive periods for developmental toxicity of orally administered artesunate in the rat. Birth Defects Res B Dev Reprod Toxicol. 2008;83:407-17

10. Clark RL, White TE, Clode SA, Gaunt I, Winstanley P, Ward SA. Developmental toxicity of artesunate and an artesunate combination in the rat and rabbit. Birth Defects Res B Dev Reprod Toxicol. 2004;71:380-94.

11. Clark RL, Arima A, Makori N, Nakata Y, Bernard F, Gristwood W, et al. Artesunate: developmental toxicity and toxicokinetics in monkeys. Birth Defects Res B Dev Reprod Toxicol. 2008:83:418-34

12. Gomes C, Boareto AC, Dalsenter PR. Clinical and non-clinical safety of artemisinin derivatives in pregnancy. Reprod Toxicol. 2016;65:194-203.

13. World Health Organization. Methods for surveillance of antimalarial drug efficacy. Geneva: World Health Organization; 2009.

14. WorldWide Antimalarial Resistance Network (WWARN). Malaria Case Record Form. 2017. (http://www.wwarn.org/tools-resources/procedures/ malaria-case-record-form-crf). Accessed 7 Apr 2017.

15. Ward SA, Sevene EJ, Hastings IM, Nosten F, McGready R. Antimalarial drugs and pregnancy: safety, pharmacokinetics, and pharmacovigilance. Lancet Infect Dis. 2007;7:136-44.

16. Nosten F, McGready R, d'Alessandro U, Bonell A, Verhoeff F, Menendez $C$, et al. Antimalarial drugs in pregnancy: a review. Curr Drug Saf. 2006;1:1-15.

17. McGready R, Nosten F. Which drug is effective and safe for acute malaria in pregnancy? Reviewing the evidence. Drug Dev Res. 2010;71:56-68.

18. Manyando C, Kayentao K, D'Alessandro U, Okafor HU, Juma E, Hamed K. A systematic review of the safety and efficacy of artemether-lumefantrine against uncomplicated Plasmodium falciparum malaria during pregnancy. Malar J. 2012;11:141.

19. Gutman J, Kovacs S, Dorsey G, Stergachis A, Ter Kuile FO. Safety, tolerability, and efficacy of repeated doses of dihydroartemisinin-piperaquine for prevention and treatment of malaria: a systematic review and metaanalysis. Lancet Infect Dis. 2017;17:184-93.

20. Kovacs SD, van Eijk AM, Sevene E, Dellicour S, Weiss NS, Emerson S, et al. The safety of artemisinin derivatives for the treatment of malaria in the 2nd or 3rd trimester of pregnancy: a systematic review and meta-analysis. PLOS ONE. 2016;11:e0164963.
21. Dellicour S, Sevene E, McGready R, Tinto H, Mosha D, Manyando C, et al. First-trimester artemisinin derivatives and quinine treatments and the risk of adverse pregnancy outcomes in Africa and Asia: a meta-analysis of observational studies. PLoS Med. 2017;14:e1002290.

22. Clark RL. Animal embryotoxicity studies of key non-artemisinin antimalarials and use in women in the first trimester. Birth Defects Res. 2017:109:1075-126.

23. Moore KA, Simpson JA, Paw MK, Pimanpanarak M, Wiladphaingern J, Rijken MJ, et al. Safety of artemisinins in first trimester of prospectively followed pregnancies: an observational study. Lancet Infect Dis. 2016:16:576-83.

24. Liberati A, Altman DG, Tetzlaff J, Mulrow C, Gotzsche PC, loannidis JP. The PRISMA statement for reporting systematic reviews and meta-analyses of studies that evaluate health care interventions: explanation and elaboration. PLoS Med. 2009;6:e1000100.

25. World Health Organization. Guidelines for the treatment of malaria. 3rd ed. Geneva: World Health Organization; 2015.

26. Naing $T$, Win $H$, Nwe $Y Y$. Falciparum malaria and pregnancy: relationship and treatment response. Southeast Asian J Trop Med Public Health. 1988;19:253-8.

27. Harinasuta T, Kietinun S, Somlaw SB, Somlaw SP, Bunnag D, Sheth UK, et al. A clinical trial of mefloquine on multi-resistant falciparum malaria in pregnant women in Thailand. Bulletin de la Societe Francaise de Parasitologie. 1990;419.

28. Nosten F, ter Kuile F, Thwai KL, Maelankirri L, White NJ. Spiramycin does not potentiate quinine treatment of falciparum malaria in pregnancy. Trans R Soc Trop Med Hyg. 1993;87:305-6.

29. Sowunmi A, Oduola AM, Ogundahunsi OA, Fehintola FA, Ilesanmi OA, Akinyinka OO, et al. Randomised trial of artemether versus artemether and mefloquine for the treatment of chloroquine/sufadoxine-pyrimethamine-resistant falciparum malaria during pregnancy. J Obstet Gynaecol. 1998;18:322-7.

30. Bounyasong S. Randomized trial of artesunate and mefloquine in comparison with quinine sulfate to treat $P$. falciparum malaria pregnant women. J Med Assoc Thai. 2001:84:1289-99.

31. McGready R, Brockman A, Cho T, Cho D, van Vugt M, Luxemburger C, et al Randomized comparison of mefloquine-artesunate versus quinine in the treatment of multidrug-resistant falciparum malaria in pregnancy. Trans $\mathrm{R}$ Soc Trop Med Hyg. 2000;94:689-93.

32. McGready R, Cho T, Samuel Villegas L, Brockman A, van Vugt M, et al. Randomized comparison of quinine-clindamycin versus artesunate in the treatment of falciparum malaria in pregnancy. Trans R Soc Trop Med Hyg. 2001;95:651-6.

33. McGready R, Ashley EA, Moo E, Cho T, Barends M, Hutagalung R, et al. A randomized comparison of artesunate-atovaquone-proguanil versus quinine in treatment for uncomplicated falciparum malaria during pregnancy. J Infect Dis. 2005;192:846-53.

34. Adam I, Ibrahim MH, Aelbasit IA, Elbashir MI. Low-dose quinine for treatment of chloroquine-resistant falciparum malaria in Sudanese pregnant women. East Mediterr Health J. 2004;10:554-9.

35. Kalilani L, Mofolo I, Chaponda M, Rogerson SJ, Alker AP, Kwiek JJ, et al. A randomized controlled pilot trial of azithromycin or artesunate added to sulfadoxine-pyrimethamine as treatment for malaria in pregnant women. PLOS ONE. 2007;2:e1166.

36. McGready R, Tan SO, Ashley EA, Pimanpanarak M, Viladpai-Nguen J, Phaiphun $L$, et al. A randomised controlled trial of artemether-lumefantrine versus artesunate for uncomplicated Plasmodium falciparum treatment in pregnancy. PLoS Med. 2008;5:e253.

37. Mutabingwa TK, Muze K, Ord R, Briceño M, Greenwood BM, Drakeley $C$, et al. Randomized trial of artesunate + amodiaquine, sulfadoxinepyrimethamine + amodiaquine, chlorproguanal-dapsone and SP for malaria in pregnancy in Tanzania. PLoS ONE. 2009:4:e5138.

38. Kaye DK, Nshemerirwe R, Mutyaba TS, Ndeezi G. A randomized clinical trial comparing safety, clinical and parasitological response to artemether-lumefantrine and chlorproguanil-dapsone in treatment of uncomplicated malaria in pregnancy in Mulago Hospital, Uganda. J Infect Dev Ctries. 2008;2:135-9.

39. Piola P, Nabasumba C, Turyakira E, Dhorda M, Lindegardh N, Nyehangane $D$, et al. Efficacy and safety of artemether-lumefantrine compared with quinine in pregnant women with uncomplicated Plasmodium falciparum 
malaria: an open-label, randomised, non-inferiority trial. Lancet Infect Dis. 2010;10:762-9.

40. Carmona-Fonseca J, Agudelo-García OM, Arango-Flórez E. [Therapeutic efficacy and adverse events of treatments for vivax and falciparum malaria in pregnant women in the regions of Uraba and Alto San Jorge, Colombia, 2008-2011] (in Spanish). Rev Colomb Obstet Ginecol. 2013;64:27-37.

41. Pregact Study Group, Pekyi D, Ampromfi AA, Tinto H, Traoré-Coulibaly M, Tahita MC, et al. Four artemisinin-based treatments in African pregnant women with malaria. N Engl J Med. 2016;374:913-27.

42. Nambozi M, Kabuya J-BB, Hachizovu S, Mwakazanga D, Mulenga J, Kasongo W, et al. Artemisinin-based combination therapy in pregnant women in Zambia: efficacy, safety and risk of recurrent malaria. Malar J. 2017;16:199.

43. Osarfo J, Tagbor H, Cairns M, Alifrangis M, Magnussen P. Dihydroartemisinin-piperaquine versus artesunate-amodiaquine for treatment of malaria infection in pregnancy in Ghana: an open-label, randomised, non-inferiority trial. Trop Med Int Health. 2017;22:1043-52.

44. Onyamboko MA, Fanello Cl, Turner G, Jackson N, Tarning J, Nosten F, et al. Comparison of two regimens of artemether-lumefantrine for the treatment of uncomplicated Plasmodium falciparum malaria in pregnant women in the Democratic Republic of Congo. Am J Trop Med Hyg. 2015;93(4 Suppl):6.

45. Ukah M, Badejoko O, Ogunniyi S, Loto O, Aboderin O, Fatusi A. A randomized trial of artesunate-amodiaquine versus artemether-lumefantrine for the treatment of acute uncomplicated malaria in pregnancy. Int J Gynaecol Obstet. 2015;131:41-4

46. Iribhogbe OI, Emmanuel I, Odianosen M. Comparative analysis of the safety and tolerability of fixed-dose artesunate/amodiaquine versus artemether/lumefantrine combinations for uncomplicated falciparum malaria in pregnancy: a randomized open label study. Clin Pharmacol. 2017;9:45-54.

47. Anvikar A. Effective and safe treatment for malaria in pregnancy in India: a randomised controlled trial. (CTRI/2009/091/001055). 2010.

48. McGready R. Randomised trial of 3 artemisinin combination therapy for malaria in pregnancy (NCT01054248). 2010.

49. McGready R, Stepniewska K, Edstein MD, Cho T, Gilveray G, Looareesuwan $\mathrm{S}$, et al. The pharmacokinetics of atovaquone and proguanil in pregnant women with acute falciparum malaria. Eur J Clin Pharmacol. 2003:59:545-52.

50. Adam I, Tarning J, Lindegardh N, Mahgoub H, McGready R, Nosten F. Pharmacokinetics of piperaquine in pregnant women in Sudan with uncomplicated Plasmodium falciparum malaria. Am J Trop Med Hyg. 2012;87:35-40

51. Onyamboko MA, Meshnick SR, Fleckenstein L, Koch MA, Atibu J, Lokomba $V$, et al. Pharmacokinetics and pharmacodynamics of artesunate and dihydroartemisinin following oral treatment in pregnant women with asymptomatic Plasmodium falciparum infections in Kinshasa DRC. Malar J. 2011;10:49.

52. McGready R, Phyo AP, Rijken MJ, Tarning J, Lindegardh N, Hanpithakpon $W$, et al. Artesunate/dihydroartemisinin pharmacokinetics in acute falciparum malaria in pregnancy: absorption, bioavailability, disposition and disease effects. Br J Clin Pharmacol. 2012;73:467-77.

53. Rijken MJ, McGready R, Phyo AP, Lindegardh N, Tarning J, Laochan N, et al. Pharmacokinetics of dihydroartemisinin and piperaquine in pregnant and nonpregnant women with uncomplicated falciparum malaria. Antimicrob Agents Chemother. 2011;55:5500-6.

54. Valea I, Tinto H, Traore-Coulibaly M, Toe LC, Lindegardh N, Tarning J, et al. Pharmacokinetics of co-formulated mefloquine and artesunate in pregnant and non-pregnant women with uncomplicated Plasmodium falciparum infection in Burkina Faso. J Antimicrob Chemother. 2014;69:2499-507.

55. Juma EA, Ogutu BR, Oloo F, Barwa T, Aman R. Pharmacokinetics of artemether-lumefantrine in pregnant and non-pregnant women with uncomplicated Plasmodium falciparum malaria in western Kenya. Am J Trop Med Hyg. 2014;91(Suppl 1):587.

56. Mosha D, Guidi M, Mwingira F, Abdulla S, Mercier T, Decosterd LA, et al. Population pharmacokinetics and clinical response for artemether-lumefantrine in pregnant and nonpregnant women with uncomplicated Plasmodium falciparum malaria in Tanzania. Antimicrob Agents Chemother. 2014;58:4583-92.
57. Nyunt MM, Nguyen VK, Kajubi R, Huang L, Ssebuliba J, Kiconco S, et al. Artemether-lumefantrine pharmacokinetics and clinical response are minimally altered in pregnant Ugandan women treated for uncomplicated falciparum malaria. Antimicrob Agents Chemother. 2016:60:1274-82.

58. Mutagonda RF, Kamuhabwa AAR, Minzi OMS, Massawe SN, Maganda BA, Aklillu E. Malaria prevalence, severity and treatment outcome in relation to day 7 lumefantrine plasma concentration in pregnant women. Malar J. 2016;15:278.

59. Mutagonda RF, Kamuhabwa AAR, Minzi OMS, Massawe SN, Asghar M, Homann MV, et al. Effect of pharmacogenetics on plasma lumefantrine pharmacokinetics and malaria treatment outcome in pregnant women. Malar J. 2017;16:267.

60. Adam I, Idris HM, Elbashir MI. Quinine for chloroquine-resistant falciparum malaria in pregnant Sudanese women in the first trimester. East Mediterr Health J. 2004;10:560-5.

61. Adam I, Elwasila E, Mohammed Ali DA, Elansari E, Elbashir MI. Artemether in the treatment of falciparum malaria during pregnancy in eastern Sudan. Trans R Soc Trop Med Hyg. 2004;98:509-13.

62. Adegnika AA, Breitling LP, Agnandji ST, Chai SK, Schütte D, Oyakhirome S, et al. Effectiveness of quinine monotherapy for the treatment of Plasmodium falciparum infection in pregnant women in Lambaréné, Gabon. Am J Trop Med Hyg. 2005;73:263-6.

63. Adam I, Ali DM, Abdalla MA. Artesunate plus sulfadoxine-pyrimethamine in the treatment of uncomplicated Plasmodium falciparum malaria during pregnancy in eastern Sudan. Trans R Soc Trop Med Hyg. 2006;100:632-5.

64. Ndiaye JL, Ndiaye A, Faye B, Ba M, Tine R, Ndiaye D, et al. Open-label in vivo drug study to evaluate the safety and efficacy of artesunate plus amodiaquine combination in pregnant women with uncomplicated $P$. falciparum malaria in Senegal. Trop Med Int Health. 2011;16(Suppl 1):140.

65. Iribhogbe Ol, Igue EO, Odianosen M. Assessment of the safety of nonfixed-dose combination of artesunate and amodiaquine for uncomplicated falciparum malaria in pregnancy: a nonrandomized open-label study. J Pharm Health Serv Res. 2017:8:31-8.

66. McGready R, Cho T, Cho JJ, Simpson JA, Luxemburger C, Dubowitz L, et al. Artemisinin derivatives in the treatment of falciparum malaria in pregnancy. Trans R Soc Trop Med Hyg. 1998;92:430-3.

67. McGready R, Cho T, Hkirijaroen L, Simpson J, Chongsuphajaisiddhi T, White NJ, et al. Quinine and mefloquine in the treatment of multidrugresistant Plasmodium falciparum malaria in pregnancy. Ann Trop Med Parasitol. 1998;92:643-53.

68. McGready R, Cho T, Keo NK, Thwai KL, Villegas L, Looareesuwan S, et al. Artemisinin antimalarials in pregnancy: a prospective treatment study of 539 episodes of multidrug-resistant Plasmodium falciparum. Clin Infect Dis. 2001;33:2009-16.

69. Laochan N, Zaloumis SG, Imwong M, Lek-Uthai U, Brockman A, Sriprawat $\mathrm{K}$, et al. Intervals to Plasmodium falciparum recurrence after anti-malarial treatment in pregnancy: a longitudinal prospective cohort. Malar J. 2015;14:221.

70. McGready R, Thwai KL, Cho T, Samuel Looareesuwan S, White NJ, et al. The effects of quinine and chloroquine antimalarial treatments in the first trimester of pregnancy. Trans R Soc Trop Med Hyg. 2002;96:180-4.

71. McGready R, Keo NK, Villegas L, White NJ, Looareesuwan S, Nosten F. Artesunate-atovaquone-proguanil rescue treatment of multidrug-resistant Plasmodium falciparum malaria in pregnancy: a preliminary report. Trans R Soc Trop Med Hyg. 2003;97:592-4.

72. Villegas L, Hernandez N, Vasquez C, Veliz F, Guevara M-E, Salazar B, et al. Treatment of multi drug-resistant falciparum malaria during pregnancy with mefloquine-artesunate in Venezuela: preliminary results. Am J Trop Med Hyg. 2005;73(Suppl):225.

73. Rijken MJ, McGready R, Boel ME, Barends M, Proux S, Pimanpanarak M, et al. Dihydroartemisinin-piperaquine rescue treatment of multidrugresistant Plasmodium falciparum malaria in pregnancy: a preliminary report. Am J Trop Med Hyg. 2008;78:543-5.

74. Rulisa S, Kaligirwa N, Agaba S, Karema C, Mens PF, de Vries PJ. Pharmacovigilance of artemether-lumefantrine in pregnant women followed until delivery in Rwanda. Malar J. 2012;11:225.

75. Kalilani-Phiri L, Thesing PC, Nyirenda OM, Mawindo P, Madanitsa M, Membe $G$, et al. Timing of malaria infection during pregnancy has characteristic maternal, infant and placental outcomes. PLoS ONE. 2013;8:e74643 
76. Cohee LM, Kalilani-Phiri L, Mawindo P, Joshi S, Adams M, Kenefic L, et al. Parasite dynamics in the peripheral blood and the placenta during pregnancy-associated malaria infection. Malar J. 2016;15:483.

77. Amiel-Tison C, Stewart A. Follow up studies during the first five years of life: a pervasive assessment of neurological function. Arch Dis Child. 1989;64:496-502.

78. Resch B, Gedermann A, Maurer U, Ritschl E, Muller W. Neurodevelopmental outcome of hydrocephalus following intra-/periventricular hemorrhage in preterm infants: short- and long-term results. Childs Nerv Syst. 1996;12:27-33.

79. Frankenburg WK, Dodds JB. The Denver developmental screening test. $J$ Pediatr. 1967;71:181-91.

80. Haataja L, McGready R, Arunjerdja R, Simpson JA, Mercuri E, Nosten F, et al. A new approach for neurological evaluation of infants in resourcepoor settings. Ann Trop Paediatr. 2002;22:355-68.

81. McGready R, Simpson J, Panyavudhikrai S, Loo S, Mercuri E, Haataja L, et al. Neonatal neurological testing in resource-poor settings. Ann Trop Paediatr. 2000;20:323-36.

82. WHO multicentre growth reference study group. Windows of achievement for six gross motor development milestones. Acta Paediatr. 2006;Supplement 450:86-95.

83. Rijken MJ, Rijken JA, Papageorghiou AT, Kennedy SH, Visser GH, Nosten $F$, et al. Malaria in pregnancy: the difficulties in measuring birthweight. BJOG. 2011;118:671-8.

84. McGready R, Prakash JAJ, Benjamin SJ, Watthanaworawit W, Anantatat T, Tanganuchitcharnchai A, et al. Pregnancy outcome in relation to treatment of murine typhus and scrub typhus infection: a fever cohort and a case series analysis. PLoS Negl Trop Dis. 2014;8:e3327.

85. Rogerson SJ, Hviid L, Duffy PE, Leke RF, Taylor DW. Malaria in pregnancy: pathogenesis and immunity. Lancet Infect Dis. 2007;7:105-17.

86. Briand V, Saal J, Ghafari C, Huynh BT, Fievet N, Schmiegelow C, et al. Fetal growth restriction is associated with malaria in pregnancy: a prospective longitudinal study in Benin. J Infect Dis. 2016;214:417-25.

87. Rijken MJ, Papageorghiou AT, Thiptharakun S, Kiricharoen S, Dwell SLM, Wiladphaingern J, et al. Ultrasound evidence of early fetal growth restriction after maternal malaria infection. PLoS ONE. 2012;7:e31411.

88. Villar J, Cheikh Ismail L, Victora CG, Ohuma EO, Bertino E, Altman DG, et al. International standards for newborn weight, length, and head circumference by gestational age and sex: the Newborn Cross-Sectional Study of the INTERGROWTH-21st Project. Lancet. 2014;384:857-68.
89. Dubowitz LM, Dubowitz V, Goldberg C, Keith I. Rapid assessment of gestational age at birth. Arch Dis Child. 1976;51:986-7.

90. Abbassi-Ghanavati M, Greer LG, Cunningham FG. Pregnancy and laboratory studies: a reference table for clinicians. Obstet Gynecol. 2009;114:1326-31.

91. Centers for Disease Control and Prevention. Recommendations to prevent and control iron deficiency in the United States. MMWR Recomm Rep. 1998;47:1-29.

92. De Beaudrap P, Turyakira E, Nabasumba C, Tumwebaze B, Piola P, Boum li $Y$, et al. Timing of malaria in pregnancy and impact on infant growth and morbidity: a cohort study in Uganda. Malar J. 2016:15:92.

93. Shi T, McAllister DA, O'Brien KL, Simoes EAF, Madhi SA, Gessner BD, et al. Global, regional, and national disease burden estimates of acute lower respiratory infections due to respiratory syncytial virus in young children in 2015: a systematic review and modelling study. Lancet. 2017;390:946-58

94. Desai M, Dellicour S. Effects of malaria and its treatment in early pregnancy. Lancet Infect Dis. 2012;12:359-60.

95. Turner C, Carrara V, Thien NA, Paw NM, Rijken M, McGready R, et al. Changes in the body weight of term infants, born in the tropics, during the first seven days of life. BMC Pediatr. 2013;13:93.

96. Wright CM, Parkinson KN. Postnatal weight loss in term infants: what is normal and do growth charts allow for it? Arch Dis Child Fetal Neonatal Ed. 2004;89:F254-7.

97. Rijken MJ, De Livera AM, Lee SJ, Boel ME, Rungwilailaekhiri S, Wiladphaingern J, et al. Quantifying low birth weight, preterm birth and smallfor-gestational-age effects of malaria in pregnancy: a population cohort study. PLOS ONE. 2014;9:e100247.

98. Lawn JE, Blencowe H, Waiswa P, Amouzou A, Mathers C, Hogan D, et al. Stillbirths: rates, risk factors, and acceleration towards 2030. Lancet. 2016;387:587-603.

99. Saito M, Gilder ME, Nosten F, McGready R, Guérin PJ. Systematic literature review and meta-analysis of the efficacy of artemisinin-based and quinine-based treatments for uncomplicated falciparum malaria in pregnancy: methodological challenges. Malar J. 2017. https://doi.org/10.1186/ s12936-017-2135-y.

\section{Submit your next manuscript to BioMed Central and we will help you at every step:}

- We accept pre-submission inquiries

- Our selector tool helps you to find the most relevant journal

- We provide round the clock customer support

- Convenient online submission

- Thorough peer review

- Inclusion in PubMed and all major indexing services

- Maximum visibility for your research

Submit your manuscript at www.biomedcentral.com/submit
() Biomed Central 